\title{
Chapter 6 \\ Scaling Up a Quality Improvement Initiative: Lessons from Chamba District, India
}

\author{
Nigel Livesley and Praveen Kumar Sharma
}

\begin{abstract}
To improve maternal and newborn survival, the Government of India launched the Reproductive, Maternal, Neonatal, Child, and Adolescent Health initiative in 2013. The initiative provided additional support to districts in states that fell within the bottom quartile on a number of health indicators, including the State of Himachal Pradesh. This case describes (1) how a USAID-supported project introduced the QI approach in Chamba District of Himachal Pradesh, (2) how the project provided initial support to form QI teams and get improvement work on maternal and newborn care started, (3) why the district government staff decided they wanted to scale up the use of QI, (4) how the district government spread QI to new blocks and facilities, and (5) what happened after the project withdrew support. The case also offers insights about key features of improvement work.
\end{abstract}

Keywords Antenatal care $\cdot$ Delivery care $\cdot$ Essential newborn care $\cdot$ India Maternal health · Post-natal care · Quality improvement · Reproductive health · Scale-up

\section{Background and Setting}

India is home to over 1.2 billion people. It accounts for one fifth of all deliveries in the world and one quarter of all newborn deaths. The size and complexity of India create important challenges in delivering good health care.

\footnotetext{
N. Livesley $(\bowtie)$

University Research Co., LLC, Abuja, Nigeria

e-mail: nlivesley@urc-chs.com

P. K. Sharma

Formerly with University Research Co., LLC (URC), New Delhi, India 
India is divided into 29 states and 7 union territories. States are further subdivided into districts, which range in population from fewer than 10,000 people to over 11 million. All levels of the health system are involved in providing health care: the central government sets the overall policy and provides the majority of finances, while state and district governments are responsible for service delivery.

To improve maternal and newborn survival, the Government of India launched the Reproductive, Maternal, Neonatal, Child, and Adolescent Health (RMNCH+A) initiative in 2013. The RMNCH+A initiative provided additional support to the districts in each state that fell within the bottom quartile on a number of health indicators.

Different states used different approaches to improve maternal and newborn survival. One approach used by the State of Himachal Pradesh was to request a United States Agency for International Development (USAID)-funded technical assistance project with decades of expertise in quality improvement (QI) to help specific facilities in priority districts of the state to use QI methods to deliver better care and to help the district governments develop strategies to spread and institutionalize the use of QI methods. This support started in December 2013 and ended in December 2015.

Chamba District was one of the four districts in Himachal Pradesh selected for support. With a population of 500,000, Chamba has 1 district hospital, 3 sub-district hospitals, 8 community health centers (CHC), 42 primary health centers (PHC), and 170 health sub-centers (HSC). ${ }^{1}$

Table 6.1 lists the key actors involved in this improvement case at each level of the health system.

\section{Getting Started}

In September 2013, the QI project started working in India. Soon after arriving, the project director met the Joint Secretary for Reproductive and Child Health for the Government of India's Ministry of Health and Family Welfare to discuss QI and introduce the approach of the project. The Joint Secretary was interested in this approach of training frontline health workers in management skills and tools to identify and fix problems at the service delivery level. He wrote a letter to the Government of Himachal Pradesh introducing the project. The Joint Secretary also introduced the project staff to senior Himachal Pradesh officials during a visit to launch the RMNCH+A initiative in November 2013. This allowed the State Improvement Coordinator from the USAID-funded project to establish contacts with the state and district stakeholders. The Chamba District Improvement Coordinator (DIC) with the project remembers said, "Our first step was to brief the

\footnotetext{
${ }^{1}$ Primary health centers are 6-30 bed units staffed by 1 or 2 general doctors. Health sub-centers are two to six bed units staffed by nurses. Community health centers are 30 bed units staffed by at least 4 doctors, including a gynecologist and anesthesiologist.
} 
Table 6.1 Key actors in the Chamba District case

\begin{tabular}{|c|c|}
\hline Position & Role \\
\hline \multicolumn{2}{|l|}{ National government } \\
\hline $\begin{array}{l}\text { Joint Secretary for Reproductive and Child } \\
\text { Health }\end{array}$ & $\begin{array}{l}\text { Introduced the project to the state } \\
\text { government }\end{array}$ \\
\hline \multicolumn{2}{|l|}{ State government } \\
\hline Mission Director, National Health Mission & $\begin{array}{l}\text { Introduced the project to the district } \\
\text { government }\end{array}$ \\
\hline \multicolumn{2}{|l|}{ District government } \\
\hline $\begin{array}{l}\text { District Collector } \\
\text { Lead civil servant for all sectors in district } \\
\text { government }\end{array}$ & $\begin{array}{l}\text { Agreed to participate in QI program } \\
\text { Reviewed QI program progress }\end{array}$ \\
\hline $\begin{array}{l}\text { Chief Medical Officer } \\
\text { Lead civil servant in the district health sector }\end{array}$ & $\begin{array}{l}\text { Assigned QI project to initial sites } \\
\text { Requested scale-up to a new block } \\
\text { Assigned staff to act as QI coaches during } \\
\text { scale-up }\end{array}$ \\
\hline $\begin{array}{l}\text { Medical Officer Health } \\
\text { Lead technical staff in district health sector }\end{array}$ & $\begin{array}{l}\text { Mobilized staff to attend QI trainings } \\
\text { Provided oversight to QI teams }\end{array}$ \\
\hline \multicolumn{2}{|l|}{ Block government } \\
\hline Block Medical Officer, Pukhri Block & $\begin{array}{l}\text { Provide oversight to QI teams in his block } \\
\text { Communicate with district leadership }\end{array}$ \\
\hline Medical Officer at PHC in Pukhri Block & QI team member \\
\hline Staff nurse at district hospital & QI team leader \\
\hline Staff nurse at PHC in Pukhri Block & QI team leader \\
\hline Ward sister in civil hospital & QI team member \\
\hline Health supervisors & Served as QI coaches during scale-up \\
\hline Multipurpose health worker at health sub-center & QI team member \\
\hline \multicolumn{2}{|l|}{ Project staff } \\
\hline District improvement coordinator (DIC) & $\begin{array}{l}\text { Provided QI training and mentoring at } \\
\text { facilities } \\
\text { Supported peer-to-peer learning } \\
\text { Trained and mentored new coaches }\end{array}$ \\
\hline State improvement coordinator & $\begin{array}{l}\text { Supported the DIC } \\
\text { Supported district to develop scale-up plan }\end{array}$ \\
\hline National project director & $\begin{array}{l}\text { Initiated contact with the Government of } \\
\text { India } \\
\text { Supported state improvement coordinator and } \\
\text { DIC }\end{array}$ \\
\hline
\end{tabular}

district administration and health officials about the project and convince them of the positive impact they could achieve on maternal and neonatal mortality using the QI approach." During an initial introductory meeting in November 2013, the State Improvement Coordinator and DIC briefed the Chief Medical Officer (CMO) and the Medical Officer Health on the fundamentals of QI and talked about how the project could support facilities in Chamba to deliver better care. The CMO and the 
Medical Officer Health agreed that they could benefit from the project's support. They asked the DIC to meet with the district data assistant to identify facilities that could benefit from this approach.

The following week, after reviewing facility-level data with the district data assistant, the DIC met again with the CMO and Medical Officer Health to discuss which facilities they should target for the QI work. Based on what they heard, district officials and the QI project team jointly decided to start the work at the district hospital and in one $\mathrm{CHC}$, two PHCs, and one HSC within Pukhri Block. The $\mathrm{MOH}$ felt that Pukhri was a sensible choice to pilot the interventions due to its proximity to district headquarters, making it easier to monitor, and because most facilities in Pukhri were sufficiently staffed. In addition, nearly $60 \%$ of all institutional deliveries in the district occurred in the five facilities listed above, thus providing a good opportunity for the project to demonstrate the effectiveness of the QI approach across all four periods of maternal and newborn health - antenatal, intrapartum, postnatal, and neonatal.

After the initial planning, the District Collector and CMO introduced the DIC and other staff from the project to the leaders and staff at the initial facilities, so that they could present the QI project and discuss what would be required of health facility staff participating in the intervention. Project staff explained that they planned to come to the facilities to form QI teams, and then facility staff and project staff would work together to improve quality of maternal and newborn health. A staff nurse at the regional hospital recalled, "After meeting the QI project staff, some of us were a bit skeptical because we were already providing services $24 \times 7$, but others were excited by the possibility of doing something new!"

In particular, the Block Medical Officer (BMO) for Pukhri was not initially enthusiastic about the selection of his block. He complained to the CMO, "Why always Pukhri? How is it that we are the first block to get selected for any pilot in the district? Our teams are already overloaded with deliveries and newborn services."

There was also considerable skepticism about external people providing support. The staff were initially distrustful of the DIC and viewed him as an outsider since he was not from the local health system. Many worried that he would highlight gaps in care to district and state leadership, creating "new problems" for them. Others questioned his ability to effect change and improve care in the facilities, given that he is not a doctor or nurse and therefor lacks the medical training that the facility staff have. "Who is he to tell us what to do?!" staff protested. However, the DIC persevered. Slowly, he earned their trust by continuously interacting with them in a respectful manner and taking all decisions in consultation and through mutual agreement, which reduced resistance. The Medical Officer Health remembers, "His approach made facility staff feel that he is assisting them; not directing them to do things. When the staff realized that the DIC is there to help and guide them, they started co-operating with him." 


\section{Initial Organization of the Improvement Work}

The process of setting objectives went through several iterations. First, a broad set of aims was taken up with the district officials. Project staff and district officials discussed the level of quality they would like to achieve for antenatal care (ANC), delivery, postnatal care (PNC), and essential newborn care (ENC) services. The parties then agreed on a set of specific aims to reach the expected level of quality, such as ensuring that hemoglobin and blood pressure are measured and patient history is taken during antenatal care to identify, refer, or manage high-risk pregnancies; administering oxytocin to women within one minute of delivery; monitoring postnatal vitals per protocol (11 times in 6 hours); and providing vitamin $\mathrm{K}$ to all newborns.

The DIC then worked with the facility staff to collect baseline data about these initial aims from the previous 6 months (going back to July 2013). At the same time, the CMO, Medical Officer Health, and the BMO validated each of these aims for their consistency with the government $\mathrm{RMNCH}+\mathrm{A}$ guidelines of the National Health Mission.

After the district leaders and project staff finalized the general set of aims, the project team organized an initial training for the facility staff at the government training facility. Over the span of 2 days, the State Improvement Coordinator and DIC trained 45 government staff in seven basic steps to improve care (see Box 6.1). Training participants were invited through a letter from the CMO and included senior staff from the district, block, and each of the five facilities, as well as clinical staff involved in care for infants and pregnant and delivering women.

\section{Box 6.1 Seven Steps to Improve Care}

1. Decide what you are trying to achieve

2. Get a team together to work on this goal

3. Think about why you are not currently reaching your goal

4. Come up with a simple measurement plan

5. Come up with some possible solutions

6. Test these ideas on a small scale (a few patients or a few hours)

7. Apply the successful ideas to your whole ward or clinic

During the workshop, the facilitators introduced the aims from which the facility staff could choose to work. As the participants were choosing aims, they expressed concerns about how feasible it would be to meet some of these aims given their workload. For example, they flatly refused to work on increasing the number of times a woman was assessed after delivery to the 11 times in the first 6 hours as stipulated in government guidelines. The State Improvement Coordinator and DIC did not emphasize these contentious areas. Instead, they asked the participants to focus initially on the specific aims that had less resistance from the group, such as giving oxytocin after delivery and improving antenatal care. 
After the initial training, the facility staff were asked to go back to their facilities and follow the seven steps to improve care. One of the first things that the participants did upon returning to their facilities was to form one QI team per facility. To do this, the senior staff who participated in the training appointed the team members and outlined the aims of the improvement project to the QI team members. Thereafter, the DIC visited each team every 2-4 weeks and spent, on average, half a day helping them learn how to practically apply improvement methods to achieve their chosen aim. During these coaching visits, the DIC would review how they were doing on the steps and help them strengthen their skills for each step. For example, one coaching visit might focus on how to better use different QI tools, such as flowcharts and fishbone diagrams, to analyze systems to understand why the facility was not currently reaching their goal; another visit might involve helping the team plan how to use small-scale tests to see if one of their ideas was feasible and effective.

When asked how these coaching visits helped them, the QI teams responded:

- "It made the staff comfortable with the DIC. Due to the frequency of meetings and the kind of facilitation they provided, they created an environment where staff felt comfortable discussing evidence and their experience and felt involved in the process of improving the quality of services." Medical Officer, Primary Health Center

- "During the meetings, we used to brainstorm a lot, analyzing causes to the problem, what can be done to solve them, and how to implement them." Block Medical Officer

- "The coaching visits by the project DIC played a critical role in making the facility staff comfortable with the process and integrating it into their practice." Medical Officer Health.

In addition to the coaching visits, the project provided support through bimonthly learning sessions where the teams came together to discuss what they had been working on for the past 2 months. The QI meetings and learning sessions not only built an environment of reflection and learning, it created a sense of teamwork. One staff nurse at the regional hospital remembered, "The exchange of lessons and experiences not only helped us learn, but also made us feel connected as one team, all working to address one problem. We were exchanging experiences beyond the aims we had undertaken!"

Teams shared learning in many different ways. For example, nurses at PHC Pukhri shot short video clips on their mobile phones to share how they had changed care to make it easier for staff to give vitamin $\mathrm{K}$ and oxytocin. These clips helped communicate the details of how the labor room was organized and how care was provided, making it easier for staff from other facilities to understand the specific changes.

A third component of support was clinical trainings. Whenever the QI teams and the DIC identified additional training needs, trainings independent of learning sessions were conducted. Initially, the project provided training on technical issues for the staff, like testing of hemoglobin, injection of vitamin $\mathrm{K}$ in newborns, and the use 
of oxytocin for managing the risk of postpartum hemorrhage. Later, they coordinated with state officials to conduct training on safe delivery and newborn care and resuscitation. For these trainings, the government would provide their trainers, either from the regional hospital or from the state level, and the project would provide logistic support. This arrangement improved district participation in and ownership of the QI work.

\section{Measurement and Results}

In initiating the improvement project, one of the first steps for teams was to set up data systems, with the help of the project staff, to support the work. In most cases, the existing government data systems were insufficient since they had limited detail on processes of care and had data quality issues. Often, health workers submitted inaccurate data to avoid getting in trouble - for example, recording that a woman had her hemoglobin measured in the antenatal period even if that was not true - and thus, problems were hidden.

The project staff helped the facility staff design simple tools to measure performance on the indicators related to their chosen aims. For example, they added new columns or rows into existing data collection sheets to record data that was relevant to their aims. The teams kept the data for their QI projects with themselves initially. Because they were not sharing them and because they were using them for their own purposes, the quality and validity of the data were substantially better than the data that they reported to the district.

Within a few months of starting the improvement work, the teams started to see evidence of substantial improvements in processes of care. Figure 6.1 shows improvement in the percentage of women receiving correct diagnostic care and an increase in the percentage of women being identified with high-risk conditions.

\section{Institutionalizing and Spreading QI from 5 to 43 Facilities}

In May 2014, after 5 months of work, key stakeholders and QI team members met to share experiences and results. At this learning session, the CMO was impressed that all five facilities had achieved their stated aims and were sustaining their results. These results generated a lot of interest among the BMOs from blocks outside of Pukhri. The BMO from Pukhri, who was originally skeptical of this work and upset that the CMO had selected Pukhri as the pilot block, recounts that after seeing the results of the intervention in Pukhri, some of the other BMOs complained to the CMO of preferential treatment to Pukhri Block and requested the inclusion of their blocks as well in interventions to improve quality of maternal and newborn health services. 


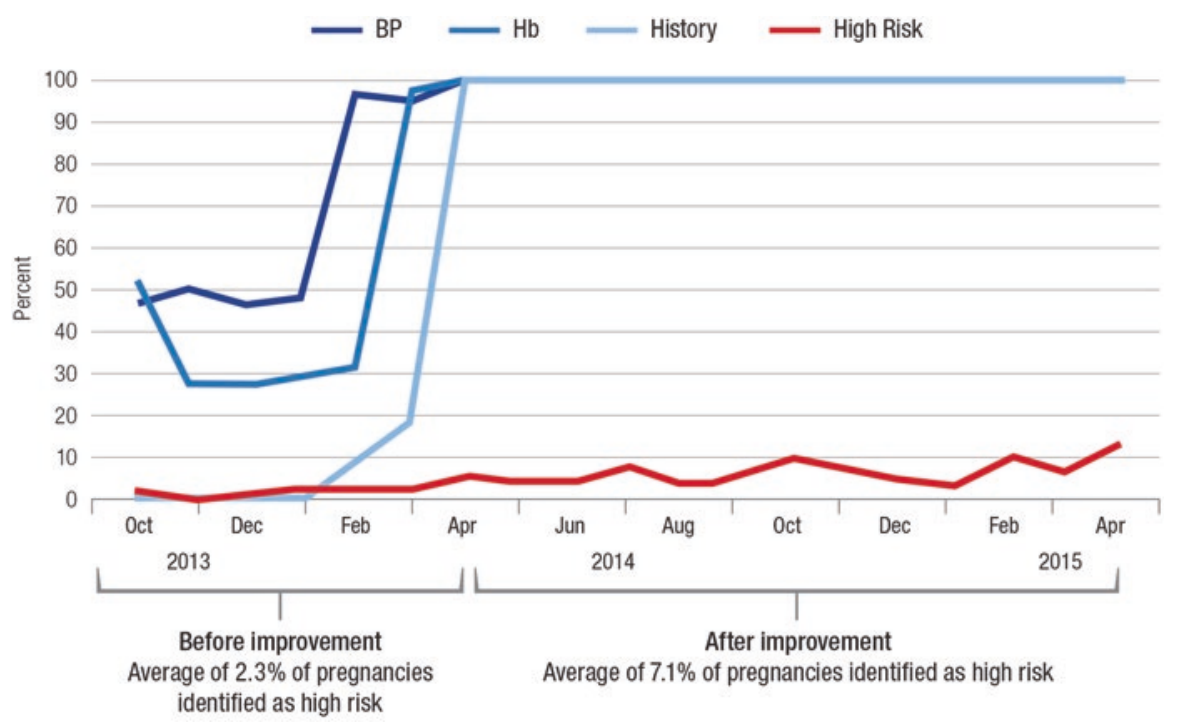

Fig. 6.1 Percentage of women coming to the antenatal clinics in five facilities having a full history taken and hemoglobin and blood pressure measured and the percentage of women being identified with high-risk conditions

Inspired by the results, the BMOs in the other blocks started telling their staff to work on the same aims as the facilities in Pukhri. The ward sister from the civil hospital shared her experience working at one of the facilities that was told to replicate Pukhri's success: "On the instructions of our medical officer, we started checking hemoglobin and blood pressure levels more frequently during antenatal care check-ups, giving an injection of oxytocin to mothers after delivery, and giving an injection of vitamin $K$ to newborns. There was a lot of improvement, but for some reason we were unable to achieve and sustain the high level of results as in the QI project-supported facilities. Therefore, the SMO was keen to get the QI project working with us."

At this point, the district leadership realized that simply setting specific aims and telling people to do better was not leading to results. They realized that the QI project must be providing a different type of support, so they asked the project to help them spread the QI model to two new blocks. The focus was more ambitious than simply improving the specific elements of care addressed in the previously supported facilities. Instead, the government wanted their own staff to be able to use QI approaches for any clinical area.

The leadership selected Choori Block because of its proximity to the district headquarters and Samote Block because of its distance from the district headquarters. District leadership also decided that existing Health Supervisors would take over the coaching role previously carried out by the DIC. "We wanted to see whether or not these interventions will work as effectively without active oversight from the 
external project," recalled the Medical Officer Health. They also wanted to see how well the Health Supervisors could perform the role of the DIC, so they included more health sub-centers (HSCs) in the spread facilities.

Between May and September 2014, the QI project staff supported the Chamba District government to develop a QI guideline detailing the roles and responsibilities of staff involved in the QI work. The guideline was based on how the project had supported the initial five facilities and highlighted three main organizational structures required to implement a QI project: facility-based QI teams, a managerial structure within and outside the facilities to support these teams, and a leadership structure that provides a clear direction for improvement as well as oversight and support during implementation. The guideline outlined key roles and responsibilities within these structures:

\section{- QI Teams.}

- The leaders of each facility were each expected to form a QI team that would select initial aims of importance to them and then follow the other seven steps for improvement. The teams were expected to report on the progress of their improvement projects and share learning.

- Managerial Structure.

- The managerial structure was composed of the BMO, who would support the larger facilities in each block, and the health supervisors, who would support the sub-centers. These staff assumed the role of the QI coach and visited each facility at least once a month to help the staff learn and implement QI projects. They were also asked to communicate with senior managers to help address issues, such as logistics, which were not always addressable at the facility level. The QI project provided 2 days of QI training to these staff, similar to the training that they provided to their own DIC.

- Leadership Structure.

- The leadership structure was formed by block and district leaders. They ensured that all facilities understood their improvement priorities and also assigned time during all block and district meetings to discuss the QI work at the facilities. This structure also ensured that government funds were made available for QI activities, including QI training, coaching, and learning sessions.

With the structures in place and key actors informed of their roles, QI projects started in the 38 new facilities in September 2014. Leading up to the spread of the QI intervention, the district leadership had taken other steps to improve care in the scale-up or spread facilities, beyond the initial action of simply telling the sites that they needed to provide basic care at the same level as the sites with improvement teams. For example, in May 2014, the district provided the new sites with classroom training from government trainers on intrapartum care and the standards they were 


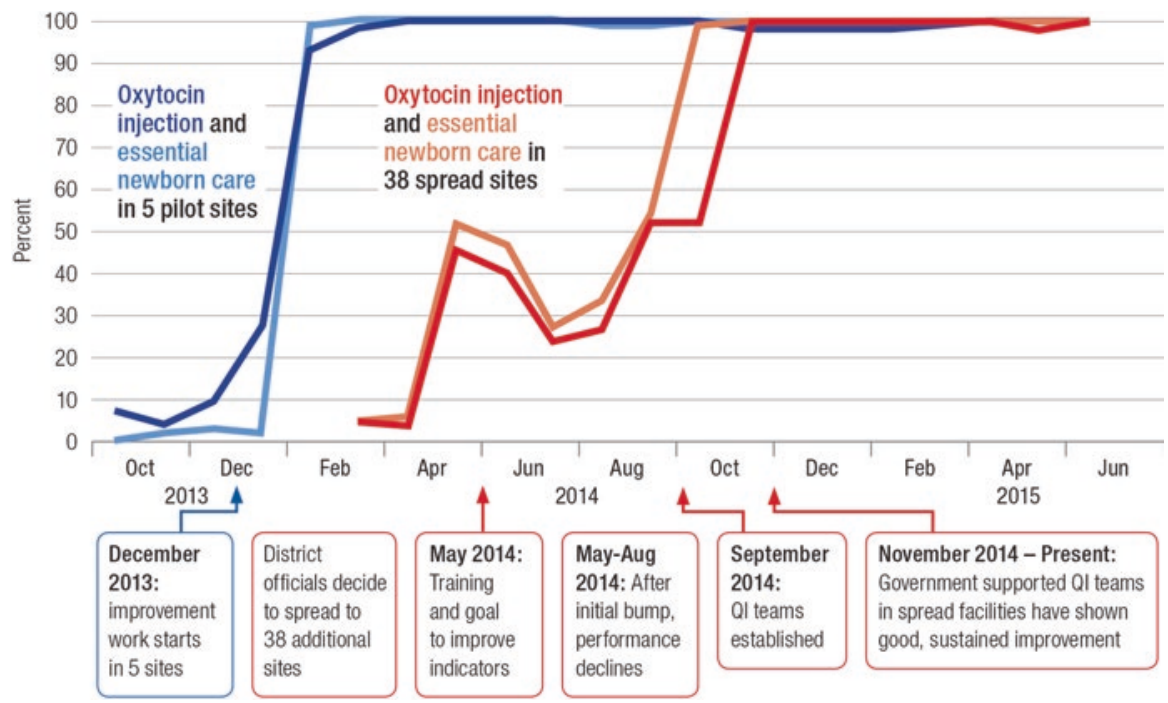

Fig. 6.2 Percentage increase in oxytocin injection and essential newborn care in 5 pilot sites and 38 spread sites, Chamba District, Himachal Pradesh, India (Oct 2013-Jun 2015)

supposed to follow. They also asked the spread sites to send monthly reports on their progress. However, as the nurse at the start of this section observed (and the data in Fig. 6.2 confirm), these interventions led to some moderate, short-term improvement, which facilities struggled to sustain. It was only when the new sites started using QI methods in September 2014 to address the poor processes at the root of these outcomes that they saw sustained improvement.

Figure 6.2 shows the data for oxytocin administration and delivery of components of essential newborn care in the 5 original QI sites and 38 spread sites.

\section{Sustainability}

The project ended support to Chamba District in December 2015 due to changes in funding. During 2016, the State Government of Himachal Pradesh developed a plan to scale up QI support in all districts based on the experiences in Chamba. In January 2017, more than a year after the project had withdrawn support, the State Improvement Coordinator revisited Chamba while working with the government on their statewide plan.

He visited two sites that had been supported directly by the project and one spread facility. All facilities had sustained improvement on the original aims and were continuing data collection related to these aims. However, they had not picked new aims nor trained new staff on QI approaches. Speaking with a Health Supervisor 
who had been supporting spread facilities, he learned that the Health Supervisor had continued coaching for around 4 months after the project left, but then stopped when the CMO, who had led this initiative, was transferred to another district and the new leaders did not ask for updates on the QI work.

The statewide plan has incorporated the learning from the initial QI work, the spread through the government, and what happened after the project closed and has a strong emphasis on setting up and supporting formal structures and systems to support QI at all levels of the health system.

\section{Reflection}

The work in Chamba highlights six important features of improvement work:

- First, it is possible to get rapid results. In the sites supported by the QI project directly, new improvement teams were able to achieve dramatic improvements in routine antenatal and intrapartum care within weeks.

- Second, results are critical to getting buy-in from leaders and other stakeholders. There was considerable skepticism to QI at the beginning in Chamba. This was partly because people thought that they had too few resources to provide better care and partly because there was reluctance to having external people provide help. Getting results early changed this perception. The impression in the district within months was that the QI methods were relevant to Chamba and that it was worth working with the external group to learn this new approach.

- Third, leadership is essential. The key figure in this case study is the Chief Medical Officer who was impressed by results and pushed the rest of the health team in the district to start to use this approach in other blocks and facilities. Without such leadership, it is unlikely that such rapid improvement would have occurred. After he and the project left, structures to support improvement were no longer maintained.

- Fourth, government staff were quickly able to pick up QI methods and use them to improve care. Helping the district develop strategies to integrate QI methods in existing systems at the facility, management, and leadership levels was critical to this success.

- Fifth, some problems require the use of improvement methods to fix. The unsustainable improvement in oxytocin and essential newborn care in spread sites after the training, introduction of standards, and supervision interventions, and the subsequent rapid improvement with the spread of improvement methods are evidence of this.

- Sixth, some elements of QI are more sustainable than others. The facilities visited more than a year after the end of external support continued to have data showing good performance on the aims that the QI teams had worked on. These improvements were sustained even in the facilities with extensive staff turnover. The systems to support new and ongoing QI, however, were no longer active. 
Acknowledgments The QI technical assistance to Chamba District described in this case was supported by the USAID Office of Health Systems through the USAID Applying Science to Strengthen and Improve Systems Project, implemented by University Research Co., LLC under Cooperative Agreement Number AID-OAA-A-12-00101.

Open Access This chapter is licensed under the terms of the Creative Commons Attribution 4.0 International License (http://creativecommons.org/licenses/by/4.0/), which permits use, sharing, adaptation, distribution and reproduction in any medium or format, as long as you give appropriate credit to the original author(s) and the source, provide a link to the Creative Commons licence and indicate if changes were made.

The images or other third party material in this chapter are included in the chapter's Creative Commons licence, unless indicated otherwise in a credit line to the material. If material is not included in the chapter's Creative Commons licence and your intended use is not permitted by statutory regulation or exceeds the permitted use, you will need to obtain permission directly from the copyright holder.

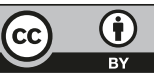

